\title{
Extremely High Expression of Antisense RNA for Wilms' Tumor 1 in Active 0steoclasts
}

\section{Suppression of Wilms' Tumor 1 Protein Expression during Osteoclastogenesis}

\author{
Yin-Ji Li, ${ }^{*}$ Akiko Kukita, ${ }^{\dagger}$ Yukari Kyumoto-Nakamura, ${ }^{*}$ and Toshio Kukita*
}

From the Division of Molecular Cell Biology and Oral Anatomy, * Division of Oral Biological Sciences, Faculty of Dental Science, Kyushu University, Fukuoka; and the Department of Microbiology, ${ }^{\dagger}$ Faculty of Medicine, Saga University, Saga, Japan

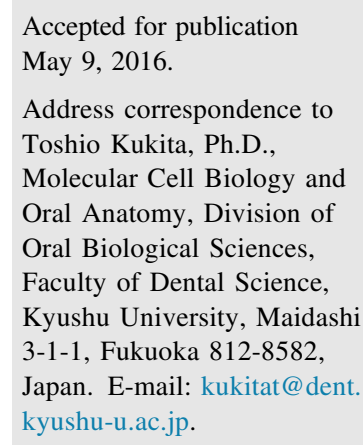

\begin{abstract}
Wilms' tumor 1 (WT1), a zinc-finger transcription regulator of the early growth response family, identified as the product of a tumor suppressor gene of Wilms' tumors, bears potential ability to induce macrophage differentiation in blood cell differentiation. Herein, we examined the involvement of WT1 in the regulation of osteoclastogenesis. We detected a high level of WT1 protein expression in osteoclast precursors; however, WT1 expression was markedly suppressed during osteoclastogenesis. We examined expression of WT1 transcripts in bone tissue by RNA in situ hybridization. We found a high level of antisense transcripts in osteoclasts actively resorbing bone in mandible of newborn rats. Expression of antisense WT1 RNA in mandible was also confirmed by Northern blot analysis and strandspecific RT-PCR. Overexpression of antisense WT1 RNA in RAW-D cells, an osteoclast precursor cell line, resulted in a marked enhancement of osteoclastogenesis, suggesting that antisense WT1 RNA functions to suppress expression of WT1 protein in osteoclastogenesis. High level expression of antisense WT1 RNA may contribute to commitment to osteoclastogenesis, and may allow osteoclasts to maintain or stabilize their differentiation state. (Am J Pathol 2016, 186: 2317-2325; http://dx.doi.org/ 10.1016/j.ajpath.2016.05.005)
\end{abstract}

Human genome projects have shown that a relatively small fraction of genomic sequences are used for encoding proteins. For many years, other genomic sequences that do not encode proteins had been thought to be meaningless DNA. ${ }^{1}$ However, discovery of regulatory RNAs has clarified the important roles of these DNAs as templates for regulatory RNAs. $^{2-4}$ miRNAs, regulatory RNAs transcribed from such noncoding genomic DNA, provide an abundant source of small interference RNAs that specifically silence gene expression of specific genes. ${ }^{2}$ Recently, antisense RNAs, which are generally transcribed from the opposite DNA strand to that for mRNAs, have been recognized as important regulatory RNAs. ${ }^{5,6}$ Through several molecular mechanisms involving the transcription collision model, transcription of the antisense RNA results in specific blocking of the
mRNA. ${ }^{7}$ One of the most profoundly investigated antisense RNA is Tsix, which mediates imprinting in X-chromosome inactivation. ${ }^{8-12}$ Antisense RNAs also play important roles in inducing mutation in hypervariable regions of immunoglobulin variable region genes in B-cell development. ${ }^{13,14}$ Continued progress in this area has demonstrated crucial roles of regulatory RNAs in a range of biological processes, including cell growth, differentiation, maintenance of stem cell populations, and tumorigenesis. ${ }^{15-17}$

Supported in part by a Japan Society for Promotion of Science grant-inaid for Scientific Research (Challenging Exploratory Research) project 23659860, 26670803, and 15K15677.

Disclosures: None declared. 
The Wilms' tumor suppressor gene encodes a zinc finger transcription factor belonging to the EGR family, Wilms' tumor 1 (WT1), which is known to be implicated in both normal kidney development and tumorigenesis. ${ }^{18}$ In normal kidney development, WT1 is required for the development of nephrons. Recently, it has also been shown that WT1 acts as a critical transcription factor in development of the cardiovascular system. ${ }^{19}$ During hematopoiesis, WT1 is highly expressed in hematopoietic progenitors, ${ }^{20}$ and most human acute leukemia contains high levels of wild-type WT1 transcripts. $^{21-23}$ It has been reported that WT1 acts as a potent inducer of macrophage differentiation. ${ }^{24}$

Osteoclasts, which share a common progenitor cell with macrophages, are primary bone resorbing cells. ${ }^{25}$ Transcription factors having the ability to induce macrophages are expected to play regulatory roles in osteoclast differentiation. We speculated that osteoclastogenesis might be regulated by WT1, as this transcription factor has the ability to induce macrophage differentiation. ${ }^{24}$ Herein, in an examination of the possible involvement of WT1 in control of osteoclastogenesis, we investigated the expression of WT1 transcripts in osteoclasts in bone tissues. An incidental and unexpected finding of this investigation was high level expression of WT1 antisense RNA in active osteoclasts in newborn rats. Northern blot and strand-specific RT-PCR analysis also detected high levels of WT1 antisense RNA in the mandible of newborn rats, in which numerous active osteoclasts are present. We further assessed the function of antisense WT1 RNA in an in vitro culture system for evaluating osteoclastogenesis.

\section{Materials and Methods}

\section{Cell Cultures and Osteoclastogenesis}

RAW-D cells, a sub-clone of the murine macrophage cell line RAW264, which have the ability to differentiate into osteoclast-like multinucleated cells, ${ }^{26,27}$ were maintained in $\alpha$-minimal essential medium containing $10 \%$ fetal bovine serum. For osteoclastogenesis, RAW-D cells were cultured in 96-well plates $\left(6.8 \times 10^{3}\right.$ cells per well) in the presence of 20 $\mathrm{ng} / \mathrm{mL}$ receptor activator of NF- $\kappa \mathrm{B}$ ligand (RANKL) and 1 $\mathrm{ng} / \mathrm{mL}$ tumor necrosis factor- $\alpha$. After 3 days, the cells were stained for tartrate-resistant acid phosphatase, and tartrateresistant acid phosphatase-positive multinucleated cells were counted. Osteoclasts were also generated from rat bone marrow cultures as described previously. ${ }^{28,29}$ Bone marrow cells were obtained from tibia and femurs of male SD rats and cultured for 4 days in 24-well plates $\left(1 \times 10^{6}\right.$ cells per well $)$ in the presence of $10^{-8} \mathrm{~mol} / \mathrm{L} 1 \alpha, 25$-dihydroxyvitamin $\mathrm{D}_{3}, 10$ $\mathrm{ng} / \mathrm{mL}$ RANKL, and $10 \%(\mathrm{v} / \mathrm{v})$ heat-treated conditioned medium of rat osteoblastic cell line ROS17/2.8 (htROSCM).

\section{Preparation of RNA Probes}

Total RNA was prepared from adult spleen of SD rats or from rat bone marrow cultures for forming osteoclasts using
ISOGEN (Nippon Gene, Toyama, Japan). Complementary DNA fragments of rat WT1 (gb: NM_031534) were prepared from total RNA of adult spleen by RT-PCR using an RNA PCR kit (AMV) Ver2.1 (Takara, Kyoto, Japan) according to the manufacturer's protocol. Sequences of PCR primers were: WT1 sense primer: ${ }_{316}^{5^{\prime}}$ GGTACAGCCGGGGCCTGTCG $_{335} 3^{\prime}$; WT1 anti-sense primer: ${ }_{593}^{5^{\prime}}$ GAGTACTGCTGCTCGCCCAG $_{574}{ }^{3^{\prime}}$ (product size $278 \mathrm{bp}$ ). PCR products were ligated into the EcoRV site of pT7Blue-T vector (Promega, Madison, WI) (pWT1\#1-2) followed by recloning into the BamHI/HindIII sites of pBluescript II $\mathrm{KS}(+)$. The direction of the insert DNA was determined by sequencing the plasmid DNA using M13-20 primer and M13 reverse primers. The plasmid was linearized with BamH I to prepare template DNA for WT1-sense probe or with Hind III to prepare template DNA for WT1-antisense probe. Digoxigenin-labeled sense and antisense RNA probes were prepared using an in vitro RNA synthesis kit (Nippon Gene, Toyama, Japan).

\section{Animals and Treatment}

Normal, fertilized SD rats were maintained in a specific pathogen-free environment; newborn rats were used for this research. All animal experiments were performed according to the guideline for Care and Use of Animals of Kyushu University.

\section{In Situ Hybridization}

Six-day-old SD rats were anesthetized and fixed by perfusion via the left ventricle with $4 \%$ paraformaldehyde in phosphate-buffered saline (PBS). Whole blocks of mandible were dissected from rats and further fixed for 12 hours in the same fixative solution at $4^{\circ} \mathrm{C}$, washed in PBS, and then demineralized at $4^{\circ} \mathrm{C}$ for 3 days in Morse's solution [22.5\% $(\mathrm{v} / \mathrm{v})$ formic acid, $10 \%(\mathrm{w} / \mathrm{v})$ sodium citrate]. The tissues blocks were dehydrated and embedded in paraffin. Serial sections ( $4 \mu \mathrm{m}$ thick) were cut and transferred onto silanecoated glass slides. In situ hybridization was performed as described previously. ${ }^{30-32}$ After dewaxing in xylene and rehydration through an ethanol series, sections were rinsed in PBS and treated with $10 \mu \mathrm{g} / \mathrm{mL}$ proteinase K (Sigma) for 10 minutes at $37^{\circ} \mathrm{C}$, fixed in $4 \%(\mathrm{w} / \mathrm{v})$ paraformaldehyde in PBS for 10 minutes, and then incubated with $0.2 \mathrm{~mol} / \mathrm{L} \mathrm{HCl}$ for 10 minutes. The sections were then treated twice in PBS containing $0.2 \%(\mathrm{w} / \mathrm{v})$ glycine for 10 minutes, followed by rinsing in PBS. The sections were acetylated with $0.25 \%$ $(\mathrm{v} / \mathrm{v})$ acetic anhydrite in $0.1 \mathrm{mmol} / \mathrm{L}$ triethanolamine $(\mathrm{pH}$ 8.0) for 10 minutes. Digoxigenin-labeled sense and antisense RNA probes corresponding to WT1 cDNA were prepared as described above and were used for strandspecific hybridization. Hybridized digoxigenin-labeled probes were detected using a DIG Nucleic Acid Detection Kit (Roche, Basel, Switzerland) according to the manufacturer's instructions. After color development, the sections were counterstained with $0.2 \%(\mathrm{w} / \mathrm{v})$ methyl green. 


\section{Northern Blot}

Total RNA was extracted from rat mandible of 6-day-old SD rats using ISOGEN (Nippon Gene, Toyama, Japan) following the manufacturer's instructions. Samples of total RNA $(7 \mu \mathrm{g})$ were denatured at $65^{\circ} \mathrm{C}$ for 5 minutes in $50 \%$ formamide and loaded on a $1 \%(\mathrm{w} / \mathrm{v})$ agarose gel containing $6.6 \%(\mathrm{v} / \mathrm{v})$ formamide. After electrophoresis, the RNA was transferred to nylon membranes (Genescreen; NEN Research Products, Boston, MA) in $10 \times$ standard saline citrate for 18 hours and then cross-linked with UV (254 nm, $120 \mathrm{~mJ} / \mathrm{cm}^{2}$ ). The membrane was prehybridized in DIGEasyHyb (Roche) for 30 minutes at $68^{\circ} \mathrm{C}$, and hybridization was performed overnight with digoxigenin-labeled sense or antisense RNA probes corresponding to WT1 cDNA. After washing with $2 \times$ standard saline citrate containing $0.1 \%$ SDS, the membranes were incubated with blocking solution for 30 minutes at room temperature, followed by incubation with alkaline phosphatase-conjugated anti-digoxigenin antibody for 30 minutes at room temperature. The membrane was washed, and the RNA was detected by a chemiluminescence reaction with CDP-Star (Roche). Blots were treated with stripping solution $[50 \%(\mathrm{v} / \mathrm{v})$ formamide, $25 \% \mathrm{SDS}, 50 \mathrm{mmol} / \mathrm{L}$ Tris/HCl, $\mathrm{pH}$ 7.5] for 2 hours at $80^{\circ} \mathrm{C}$ and reused for another detection.

\section{Strand-Specific RT-PCR}

Total RNA was extracted from rat mandible of 6-day-old SD rats using ISOGEN (Nippon Gene), and cDNA was synthesized from $1 \mu \mathrm{g}$ total RNA with AMV Reverse Transcriptase XL (Takara Bio, Kyoto, Japan) at $50^{\circ} \mathrm{C}$ for 1 hour. For the generation of strand-specific cDNA, either sense-specific (R1493) or antisense-specific (R284) primer was used. Sense- or antisense-specific cDNA was amplified with two different primer pairs (F1077/R1493 and F455/ R708) using an RT-PCR kit (Takara Bio). PCR primer sequences to detect antisense RNA are listed in Table 1.

Table 1 Primer Sequences Utilized in Strand-Specific RT-PCR

\begin{tabular}{|c|c|}
\hline Primer name & Sequence \\
\hline \multicolumn{2}{|l|}{ WT1 sense } \\
\hline $\begin{array}{l}\text { WT1sR1493 } \\
\text { (R1493) }\end{array}$ & 5'-TCTTGGAAGTCGGATGAAGATCCA-3' \\
\hline $\begin{array}{l}\text { WT1s1077F } \\
\text { (F1077) }\end{array}$ & $5^{\prime}$-TGACTTCAAGGACTGCGAGAGA-3' \\
\hline $\begin{array}{l}\text { WT1s1493R } \\
\text { (R1493) }\end{array}$ & 5'-TCTTGGAAGTCGGATGAAGATCCA-3' \\
\hline \multicolumn{2}{|l|}{ WT1 antisense } \\
\hline $\begin{array}{l}\text { WT1asR284 } \\
\text { (R284) }\end{array}$ & 5'-ССТTCACСТTGCАСТTCTCC-3' \\
\hline $\begin{array}{l}\text { WT1as455F } \\
\text { (F455) }\end{array}$ & $5^{\prime}$-GACACCCCAGATGATGGGAA-3' \\
\hline $\begin{array}{l}\text { WT1as708R } \\
\text { (R708) }\end{array}$ & 5'-CGGAGTAACCGCATAGTGGA-3' \\
\hline
\end{tabular}

Plasmid Construct for Antisense WT1 RNA and Transfection

The expression plasmid used to produce antisense RNA for WT1 was constructed from the pMKITneo vector (kindly provided by Dr. Maruyama of Tokyo Medical and Dental University, Tokyo, Japan) having the SR $\alpha$ promoter upstream of the multiple cloning site. For encoding WT1 antisense RNA, the SpeI/EcoRI fragment excised from pWT\#1-2 plasmid (see Preparation of RNA Probe) was cloned into SpeI/EcoRI site, down-stream of $\mathrm{SR} \alpha$ promoter of pMKITneo. Accuracy of the construct was confirmed by nucleotide sequencing. Plasmid DNA was purified with a Plasmid Purification Kit (Qiagen, Valencia, CA), and transfected into RAW-D cells using the Nucleofector System (Amaxa Biosystems, Gaithersburg, MD). Briefly, $3 \times 10^{6}$ cells were transfected with 0.75 to $2 \mu \mathrm{g}$ plasmid DNA in the presence of Nucleofector reagents according to the manufacturer's protocol. The numbers of tartrateresistant acid phosphatase-positive multinucleated cells were counted after 3 days of culture in the presence of RANKL. Data were analyzed by Student's $t$-test. At initiation and end of culture, total proteins were extracted for Western blotting.

\section{Real-Time PCR Analysis}

Total RNA was extracted using Isogen (Nippon Gene). Total RNA was reverse transcribed with a PrimeScipt RT-PCR kit (Takara) by use of random primers. Real-time PCRs were performed by using SYBR Primer EX Taq (Takarabio) with a StepONePlus real-time PCR system (Applied Biosystems). The following primers were used for real-time RT-PCR analysis: mouse Ctsk (cathepsin K) sense, 5'-CTCTCGGCGTTTAATTTGGGAG-3' , antisense, 5'-CCCTGGTTCTTGACTGGAGTAACG-3'; mouse Z Zbtb7a(LRF), sense, 5'-GAGAAGAAAATCCGGGCCAAG-3', antisense, 5'-GCAGCTATCGCACTGGTATGG-3'; mouse $N$ fatc 1 sense, 5' -TCATCGGCGGGAAGAAGATG-3', antisense, 5'-AATTTGGCTTGCACAGGTCC-3'; mouse Fos sense, 5'-GAAGGGGCAAAGTAGAGCAG-3', antisense, 5'-GTTGATCTGTCTCCGCTTGG-3'; mouse Gapdh sense, 5'-TGCACCACCAACTGCTTAG- ${ }^{\prime}$, antisense, 5'-GGATGCAGGGATGATGTTC-3'. mRNA levels were normalized to Gapdh expression.

\section{Western Blot}

Cells were lysed in lysis buffer containing $1 \%(\mathrm{v} / \mathrm{v})$ Triton $\mathrm{X}-100,0.5 \%$ (v/v) NP-40, $150 \mathrm{mmol} / \mathrm{L} \mathrm{NaCl}, 50 \mathrm{mmol} / \mathrm{L}$ Tris-HCl (pH 7.4), and protease inhibitor cocktail (Sigma, St. Louis, MO). Aliquots of lysates, containing equal amounts of lysate proteins, were separated by $10 \%$ (w/v) SDS-PAGE and transferred to a nitrocellulose membrane. After blocking in 5\% nonfat dry milk in tris-buffered saline, the membrane was probed with rabbit anti-WT1 antibody 
(Santa Cruz Biotechnology, Dallas, TX), followed by rinsing in tris-buffered saline. Proteins were detected with horseradish peroxidase-conjugated anti-rabbit IgG (Amersham Biosciences, Buckinghamshire, UK). As a loading control, the membrane was stripped, reprobed with anti-actin antibody (Santa Cruz Biotechnology), and visualized by ECL Plus kit (Amersham Biosciences).

\section{Results}

\section{Expression of WT1 Protein during 0steoclastogenesis}

Immunoblotting analysis showed that RAW-D osteoclast precursor cells expressed high levels of WT1 protein when the cells were not under stimulation by osteoclastogenic factors. However, the level of WT1 protein in osteoclast precursors was markedly reduced when cells were stimulated with RANKL and tumor necrosis factor- $\alpha$ to induce osteoclast formation (Figure 1). Murine spleen cells (positive control), which are known to contain abundant hematopoietic progenitor cells, expressed high levels of WT1 (Figure 1). High levels of WT1 protein expression were also observed in rat bone marrow cells, which contain numerous hematopoietic progenitors, including osteoclast precursors.
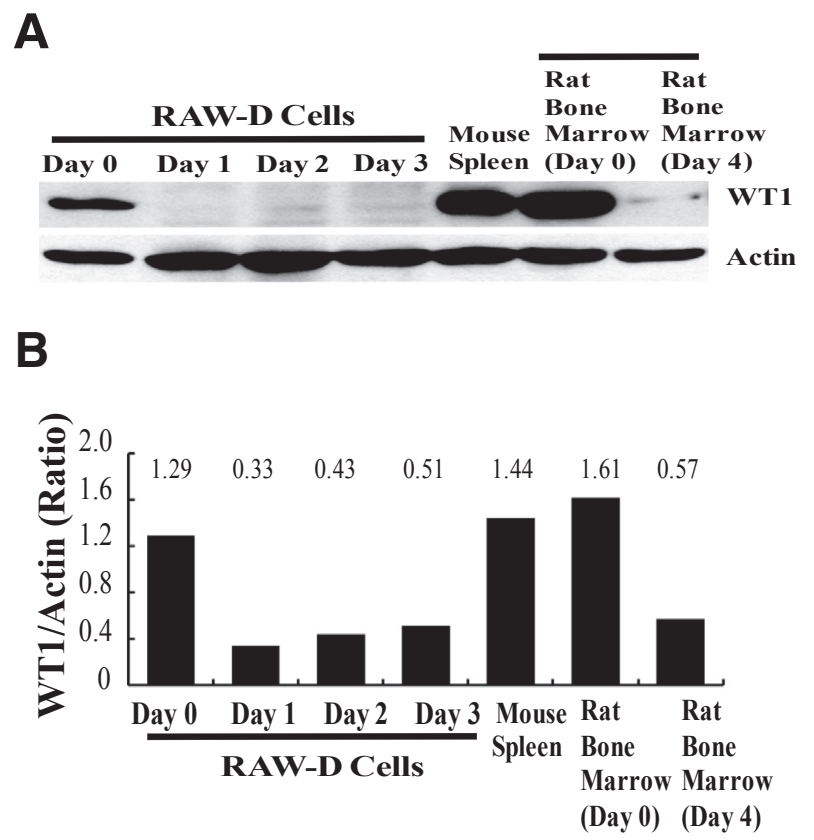

Figure 1 Expression of WT1 protein during osteoclastogenesis. Total proteins were extracted from RAW-D cells and rat bone marrow cells cultured for forming osteoclasts, as described in Materials and Methods. Total proteins were also isolated from murine spleen cells. A: Equal amounts of proteins were subjected to Western blot analysis with anti-WT1 antibody or anti-actin antibody. Lane 1 to 4 (from the left): RAW-D cells cultured for 0, 1, 2, 3 days for forming osteoclasts. Lane 5: Mouse spleen cells as positive control for WT1 expression (mouse spleen). Lanes 6 and 7: Rat bone marrow cells cultured (day 0 and day 4 ) for forming osteoclasts, as described in Materials and Methods. Actin is used as the loading control. B: The ratio of WT1/actin was calculated by NIH Scion image analyzer for each lane. Experiments were performed three times with similar results.
Marked suppression of WT1 protein expression was detected when rat bone marrow cells were stimulated to differentiate into osteoclasts (Figure 1). These data demonstrate that the expression of WT1 protein is markedly downregulated during the process of osteoclast differentiation.

\section{High Expression of Antisense WT1 RNA in Active Osteoclasts in Vivo}

To determine the expression of WT1 mRNA in vivo, we examined the expression of WT1 mRNA in the mandibles of newborn rats. Low levels of WT1 mRNA were detected in osteoclasts (Figure 2A). Unexpectedly, high expression of WT1 antisense RNA was detected in osteoclasts located on the surface of the alveolar bone adjacent to incisor tooth germ; these cells were presumed to be migrating between bone trabeculae (Figure 2B). No WT1 mRNA was detected in active osteoclasts (Figure 2, C and E), but marked expression of WT1 antisense RNA was detected in osteoclasts engulfing the tip of bone trabeculae (Figure 2, D and F). These cells may have been actively resorbing bone. These data show that osteoclasts express high levels of WT1 antisense RNA.

\section{Sense Transcripts Anti sense Transcripts}
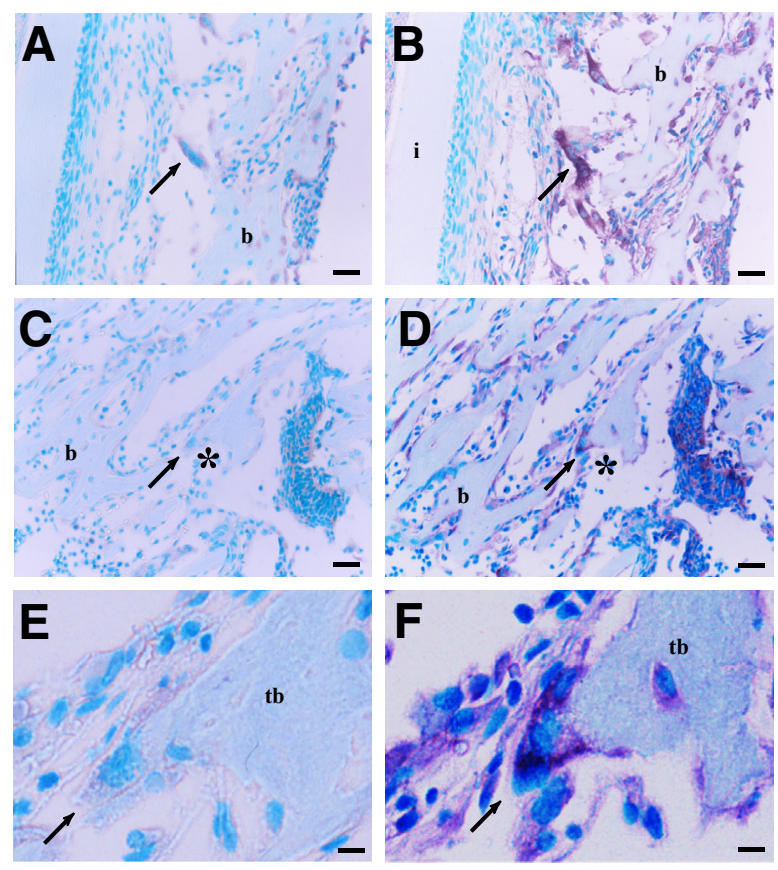

Figure 2 Extremely high expression of antisense WT1 RNA in osteoclasts in the mandible of newborn rats revealed by RNA in situ hybridization. WT1 antisense probe (A, C, and $\mathbf{E})$ or sense probe $(\mathbf{B}, \mathbf{D}$, and $\mathbf{F})$ was hybridized with tissue sections of mandible. Purple shows the transcripts. Nuclear staining was performed with methyl-green after detecting the transcripts. $\mathbf{E}$ and $\mathbf{F}$ are the high magnification view of $\mathbf{C}$ and $\mathbf{D}$ (asterisks), respectively. The left column and the right column are the serial sections ( $\mathbf{A}$ and $\mathbf{B}, \mathbf{C}$ and $\mathbf{D}, \mathbf{E}$ and $\mathbf{F}$, respectively). Arrows show the position of the typical osteoclasts. Scale bars: $50 \mu \mathrm{m}(\mathbf{A}-\mathbf{D}) ; 10 \mu \mathrm{m}$ (E and $\mathbf{F})$. b, bone; i, incisor tooth germ; tb, trabecular bone. 
A

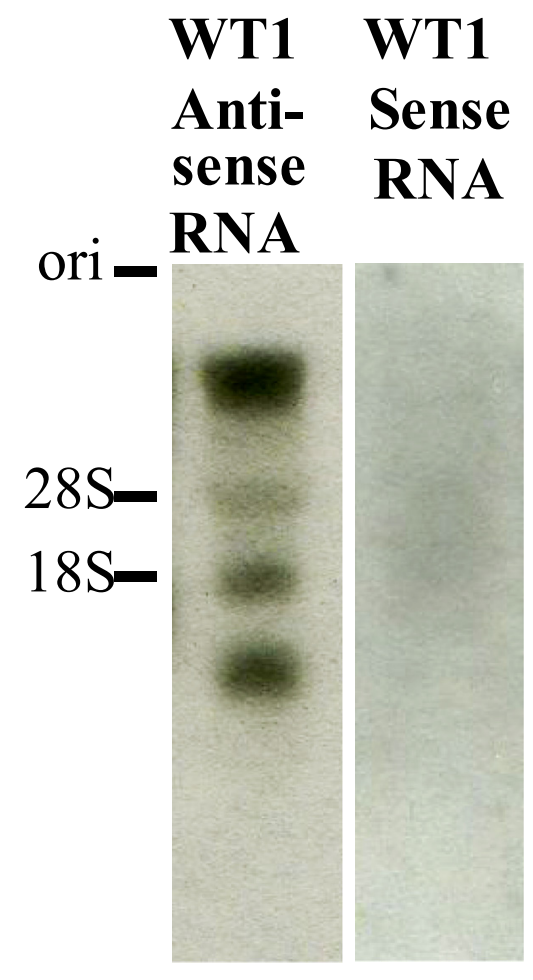

B

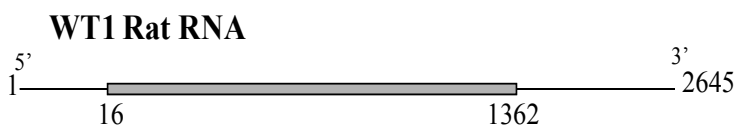

cDNA Synthesis (Reverse Transcription With Strand Specific Primer)
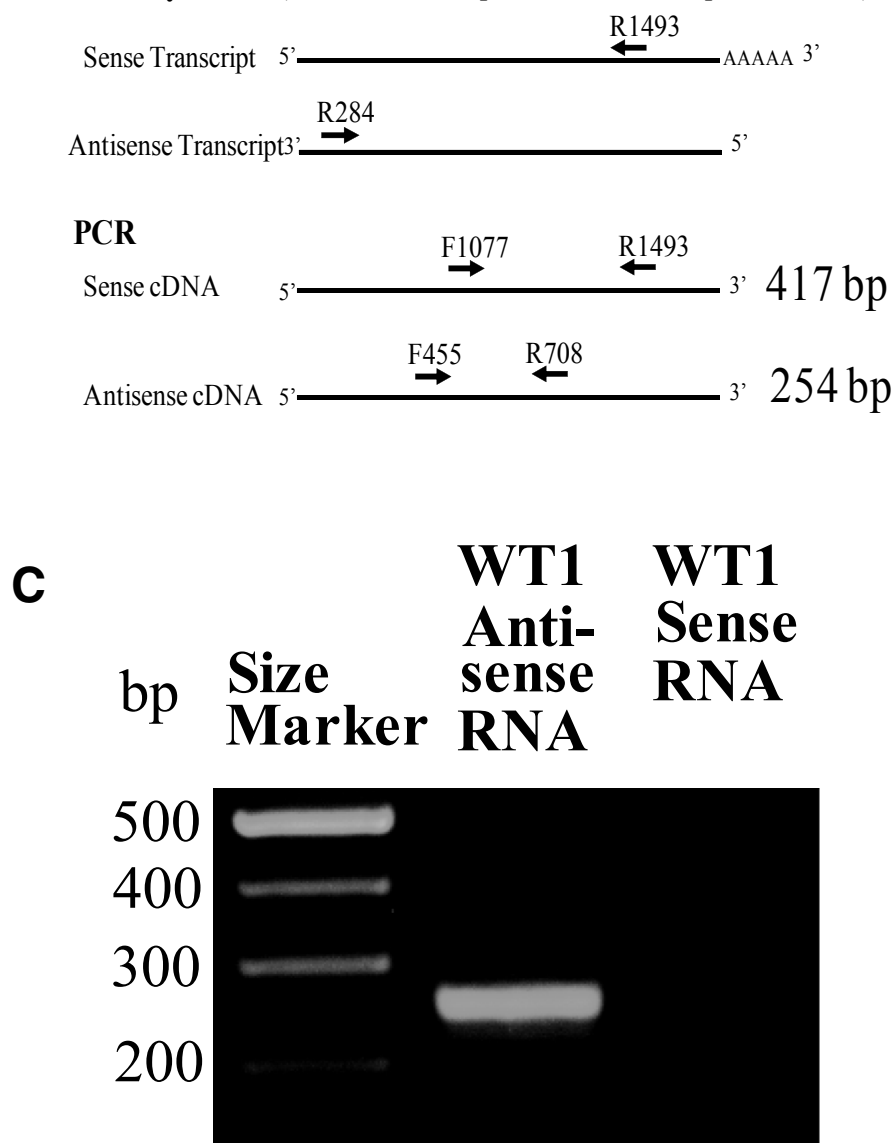

Figure 3 Detection of WT1 antisense RNA in mandible of newborn rats by Northern blotting and strand-specific RT-PCR. A: Northern blotting: Total RNAs were extracted from mandible of newborn rats. Equal amount of RNAs was subjected to agarose gel electrophoresis followed by transfer to nylon membranes and subjected to Northern blot analysis by use of the strand-specific RNA probes. Left panel: Antisense RNA transcripts detected by the sense RNA probe for WT1. Right panel: Sense RNA transcripts (mRNA) detected by antisense RNA probes. Position of the origin (ori) and the size of ribosomal RNAs (28S and 18S) are shown. B: Strategy for detecting antisense RNA using strand-specific primers. Details were described in Materials and Methods. GenBank accession number of WT1 rat RNA is NM_031534 (http://www.ncbi.nlm.nih.gov/nuccore). C: Strand-specific RT-PCR: RNAs from mandible of newborn rats were also subjected to the strand-specific RT-PCR, as described in Materials and Methods. Left lane: size marker. Middle lane: antisense RNAs. Right lane: sense RNAs (mRNAs).

We confirmed the expression of WT1 antisense RNA in mandible by Northern blot analysis and strand-specific RTPCR. The Northern blot data showed expression of antisense WT1 RNA of multiple sizes in mandible of newborn rats (Figure 3A), whereas only a faint signal corresponding to WT1 sense RNA (mRNA) was detected by Northern blot (Figure 3A). Strand-specific RT-PCR of total RNA obtained from mandible of newborn rats using a specific set of primers (Figure 3B and Table 1) detected a 254-bp PCR product, indicating the expression of antisense WT1 RNA (Figure 3C).

\section{Function of Antisense WT1 RNA in 0steoclastogenesis}

To assess the role of WT1 protein and the function of WT1 antisense RNA expressed in cells of the osteoclast lineage, an expression plasmid designed to express WT1 antisense RNA (Figure 4A) was transfected into RAW-D cells. When these transfected cells were induced to form osteoclasts, osteoclastogenesis was markedly enhanced by overexpression of WT1 antisense RNA compared to empty vector controls (Figure 4, $\mathrm{B}$ and $\mathrm{C})$. We confirmed the suppression of WT1 protein synthesis in transfected cells by Western blot (Figure 4D). The protein levels of WT1 were markedly decreased in RAW-D cells transfected with the antisense WT1 RNA expression plasmid, but transfection of empty vector had no effect on the expression of WT1 protein (Figure 4D). These data indicate that WT1 antisense RNA has the ability to stimulate osteoclastogenesis by suppressing WT1 protein expression.

To know the function of WT1 antisense RNA in the expression of several molecules related to osteoclast 

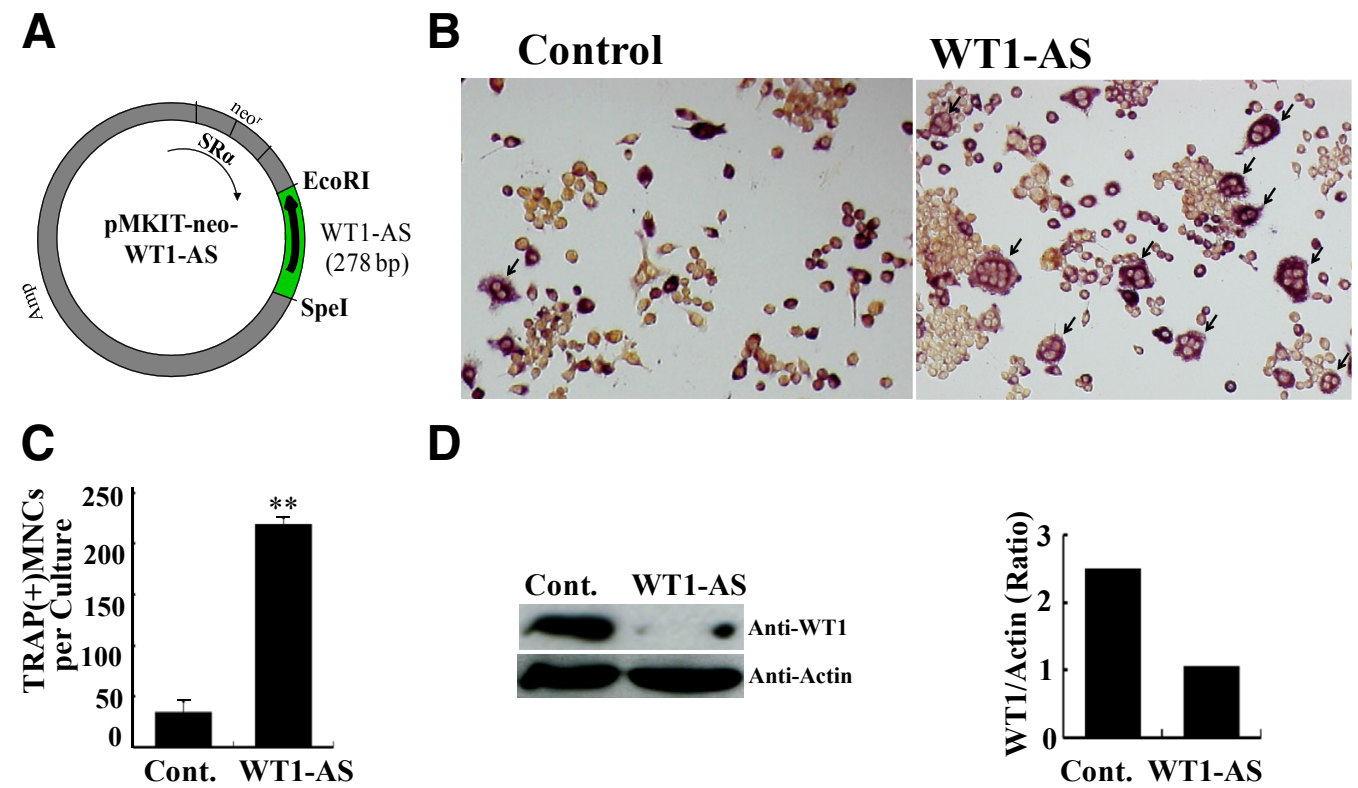

D
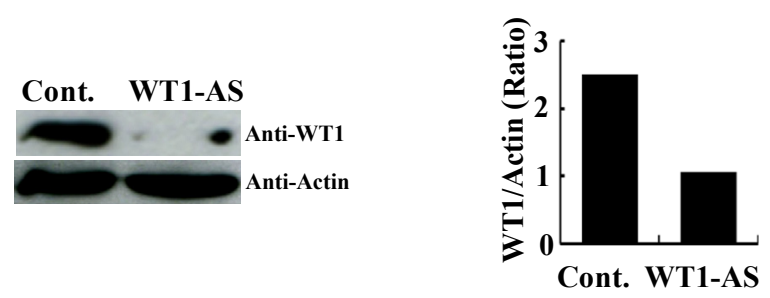

Figure 4 Marked stimulation of osteoclastogenesis by overexpressing WT1 antisense RNAs. RAW-D cells were transfected with the plasmid DNA expressing WT1 antisense RNA (WT1-AS) or with empty vector (control) and further cultured in the presence of $20 \mathrm{ng} / \mathrm{mL}$ receptor activator of NF- $\mathrm{KB}$ ligand and $1 \mathrm{ng} / \mathrm{mL}$ of tumor necrosis factor (TNF)- $\alpha$. A: Schematic demonstration of the construct expressing antisense WT1 RNA. Preparation of the construct was performed as described in Materials and Methods. B and C: Marked elevation of osteoclastogenesis by transfecting WT1-AS construct. After 3 days of culture of the transfected RAW-D cells, cells were fixed and stained for tartrate-resistant acid phosphatase (TRAP); (B) and number of TRAP-positive multinucleated cells (arrows) was counted (C). Statistical analysis was performed using paired Student's $t$-test. D: Suppression of WT1 protein by transfection of a construct expressing WT1 antisense RNA. Total cell lysates were prepared from RAW-D cells transfected with the empty vector (left lane: Cont.) or WT1 antisense RNA-expressing vector (right lane: WT1-AS), and equal amounts of proteins were subjected to Western blot analysis with anti-WT1 and anti-actin antibodies (left panel). Actin was used as a loading control. The ratio of WT1/actin was calculated by NIH Scion image analyzer (right panel). Data are expressed as means \pm SEM from quadruplicate cultures (C). ${ }^{* *} P<0.01$. Cont., control.

differentiation, we have examined the expression of Ctsk, Nfatcl, Zbtb7a (gene for OCZF/LRF), and cfos in RAW-D cells transfected with expression plasmid, which express WT1 antisense RNA. Figure 5 shows the effects of WT1 antisense RNA expression on osteoclastogenesis when transfected RAW-D cells were stimulated with RANKL for 3 days. Although WT1 antisense RNA did not significantly affect the expression of Nfatcl, cfos, and Zbtb7a, it significantly stimulated expression of Ctsk gene. These data suggest that WT1 antisense RNA has a regulatory role in gene expression required for osteoclasts, at least in the late stage of osteoclast differentiation.

\section{Discussion}

In the current study, we have found high expression of WT1 antisense RNA in mature osteoclasts. Our functional studies suggested that WT1 antisense RNA has the ability to augment osteoclastogenesis by inhibiting WT1 protein expression. We have detected high expression of WT1 protein in an osteoclast precursor cell line and in bone marrow cells before induction of osteoclastogenesis. After osteoclast induction, expression of WT1 protein was markedly suppressed. A possible molecular mechanism mediating suppression of WT1 protein expression during osteoclastogenesis was suggested by the RNA in situ hybridization analysis, which showed low levels of WT1 mRNA in multinucleated osteoclasts migrating between bone trabeculae and undetectable WT1 mRNA in activated osteoclasts adhered to the tip of bone trabeculae, but high expression of WT1 antisense RNA in these cells. Several reports have been suggested that WT1 antisense RNA regulates the expression of WT1 protein. Moorwood et $\mathrm{al}^{33}$ previously demonstrated that WT1 antisense transcripts colocalized with WT1 protein and mRNA in fetal kidney podocytes and glomeruli, consistent with a role for WT1 antisense RNA in positive regulation of WT1 expression. In contrast, Dallosso et $\mathrm{al}^{34}$ showed that WT1 antisense RNA was able to suppress WT1 protein levels in an in vitro model. In their model, WT1 antisense RNA forms a duplex with mRNA, which blocks WT1 protein synthesis. Our results are similar, and indicate that the WT1 antisense RNA regulates osteoclastogenesis through down-regulating WT1 protein synthesis during osteoclastogenesis. A high level of WT1 antisense RNA in active osteoclasts could ensure complete suppression of WT1 protein expression, which might avoid loss of differentiation capacity of osteoclasts (Figure 6). Osteoclastogenesis is controlled by several transcription factors, including c-fos, ${ }^{35}$ NFATc $1,{ }^{36} \mathrm{OCZF} /$ $\mathrm{LRF},{ }^{29,37,38}$ among others. We have examined the regulatory function of WT1 antisense RNA in the expression of 

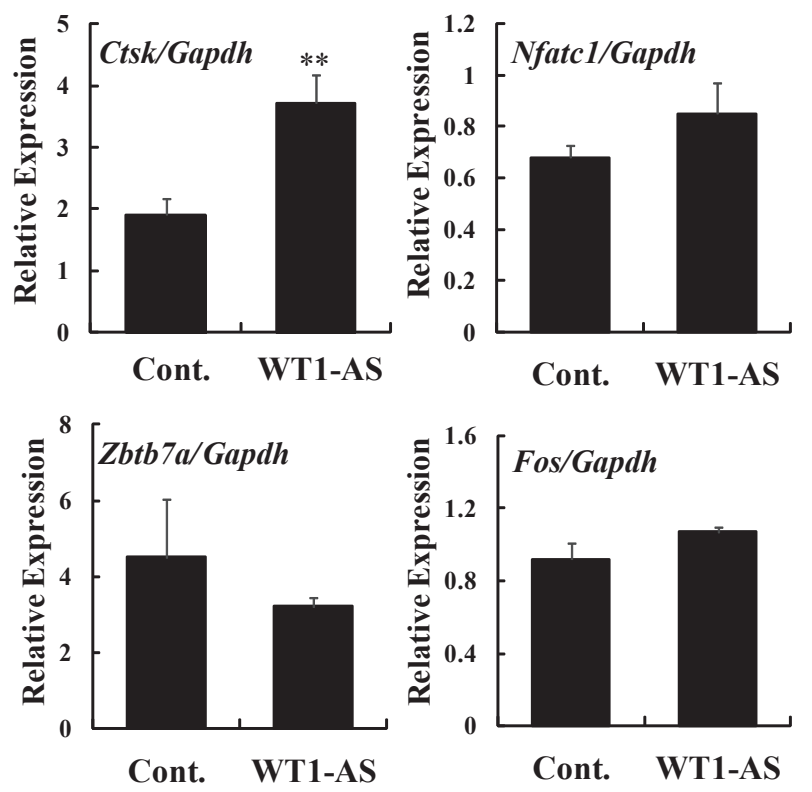

Figure 5 Significant stimulation of Ctsk gene expression by WT1 antisense RNA. RAW-D cells were transfected with $1.5 \mu \mathrm{g}$ of plasmid designed to express WT1 antisense RNA (WT1-AS) or empty vector (Cont.) followed by being stimulated with $40 \mathrm{ng} / \mathrm{mL}$ receptor activator of NF- $\mathrm{KB}$ ligand for 68 hours. Total RNA was extracted and subjected to real-time RT-PCR, as described in Materials and Methods. Experiments were performed three times with similar results. $n=4$. ${ }^{*} P<0.01$ versus control. Cont., control.

these transcription factors in late stage of osteoclastogenesis. Although statistically significant effects were not observed, there exists a tendency that WT1 antisense RNA enhanced expression of $\mathrm{Nfatcl}$ and fos. If we examined the expression of these transcription factors in earlier stages of osteoclast

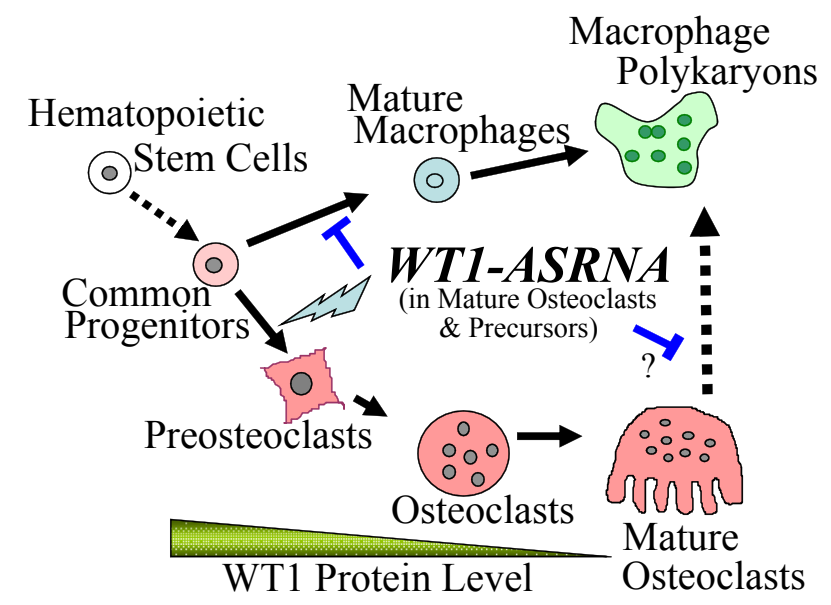

Figure 6 Schematic illustration of a hypothetical role of WT1-antisense RNA in the fine regulation of osteoclast differentiation. Macrophages and osteoclasts differentiate from a common progenitor. High expression of WT1 protein detected in osteoclast progenitors is down-regulated during osteoclast differentiation. WT1 antisense RNA (WT1-ASRNA) expressed in cells in the osteoclast lineage can have a regulatory role in the induction of osteoclastogenesis from progenitors and a regulatory role in maintaining differentiation status in mature osteoclasts. differentiation, we might successfully detect the significant induction of these transcription factors. It will be important to elucidate the functional relationship between these transcription factors and WT1 antisense RNA in the induction and regulation of osteoclastogenesis. Further extensive studies are required to elucidate the molecular mechanism of the action of WT1 antisense RNA on gene expression essential for osteoclast differentiation. In these analyses, we have detected a significant stimulation of Ctsk gene expression by WT1 antisense RNA. As the Ctsk gene product, cathepsin $\mathrm{K}$, is an essential cysteine protease required for bone resorption, induction of WT antisense RNA could have a supportive role in osteoclastic bone resorption. Extensive investigation of the relationship between the expression of WT1 antisense RNA and the activity of osteoclasts can open new avenues regarding the regulation of osteoclast activation by the antisense RNAs.

It has been shown that miR-21 induced by RANKL is essential for osteoclastogenesis, and that silencing of miR21 expression impairs osteoclastogenesis. ${ }^{39}$ Recently, it has been reported that various miRNAs, including miR-29, ${ }^{40}$ miR-31, ${ }^{41}$ miR-124, ${ }^{42}$ miR-125a, ${ }^{43}$ miR-148a ${ }^{44}$ miR$155,{ }^{45}$ and miR-223, ${ }^{46}$ are involved in the regulation of osteoclastogenesis. Krzeszinski et $\mathrm{al}^{47}$ showed that miR-34a is a suppressor of osteoclastogenesis and bone resorption, and suppresses the bone metastatic niche reducing metastasis. Several reports have described the expression of IGF2receptor antisense RNAs, which are thought to be involved in genomic imprinting. ${ }^{48,49}$ Our current findings reported herein demonstrate a possible mechanism for fine regulation related to maintenance of osteoclast differentiation states by WT1 antisense RNAs.

Dallosso et $\mathrm{al}^{34}$ defined the precise promoters of WT1 antisense transcripts in intron 1 of the murine Wtl gene, and found several antisense RNA species in kidney and ovary of different sizes that were formed through alternative splicing. In our current Northern blot experiments, we detected several WT1 antisense RNAs of different sizes, which probably reflect alternatively spliced WT1 antisense transcripts. We continue to pursue elucidation of the molecular details of these WT1 antisense RNAs detected in active osteoclasts in mandible of newborn rats. WT1 protein is highly expressed in hematopoietic progenitors and bone marrow cells before differentiation into osteoclasts. Thus, regulation of antisense RNA may provide an avenue toward development of novel therapies for controlling pathological bone resorption.

\section{Acknowledgments}

We thank Dr. Miho Matsuda (Kyushu University, Faculty of Dental Science) for helpful discussions, Dr. Eric Milner for editing the manuscript, and Dr. Kazuo Maruyama (Tokyo Medical and Dental University) for providing pMKITneo vector. 
T.K. directed the project; Y.-J.L., A.K., and T.K. wrote the manuscript; T.K. performed the in situ hybridization; Y.J.L., A.K., and Y.K.-N. performed gene expression analysis; all authors analyzed data.

\section{References}

1. Doolittle WF: Is junk DNA bunk? a critique of ENCODE. Proc Natl Acad Sci U S A 2013, 110:5294-5300

2. Pasquinelli AE: MicroRNAs and their targets: recognition, regulation and an emerging reciprocal relationship. Nat Rev Genet 2012, 13 : $271-282$

3. Luteijn MJ, Ketting RF: PIWI-interacting RNAs: from generation to transgenerational epigenetics. Nat Rev Genet 2013, 14:523-534

4. Castel SE, Martienssen RA: RNA interference in the nucleus: roles for small RNAs in transcription, epigenetics and beyond. Nat Rev Genet 2013, 14:100-112

5. Esteller M: Non-coding RNAs in human disease. Nat Rev Genet 2011, 12:861-874

6. Yelin R, Dahary D, Sorek R, Levanon EY, Goldstein O, Shoshan A, Diber A, Biton S, Tamir Y, Khosravi R, Nemzer S, Pinner E, Walach S, Bernstein J, Savitsky K, Rotman G: Widespread occurrence of antisense transcription in the human genome. Nat Biotechnol 2003, 21:379-386

7. Faghihi MA, Wahlestedt C: Regulatory roles of natural antisense transcripts. Nat Rev Mol Cell Biol 2009, 10:637-643

8. Lee JT: Gracefully ageing at $50, \mathrm{X}$-chromosome inactivation becomes a paradigm for RNA and chromatin control. Nat Rev Mol Cell Biol 2011, 12:815-826

9. Wutz A: Gene silencing in X-chromosome inactivation: advances in understanding facultative heterochromatin formation. Nat Rev Genet 2011, 12:542-553

10. Lee JT, Davidow LS, Warshawsky D: Tsix, a gene antisense to Xist at the X-inactivation centre. Nat Genet 1999, 21:400-404

11. Pasque V, Tchieu J, Karnik R, Uyeda M, Dimashkie AS, Case D, Papp B, Bonora G, Patel S, Ho R, Schmidt R, McKee R, Sado T, Tada T, Meissner A, Plath K: X-chromosome reactivation dynamics reveal stages of reprogramming to pluripotency. Cell 2014, 159:1681-1697

12. Yue M, Richard JLC, Ogawa Y: Dynamic interplay and function of multiple noncoding genes governing $\mathrm{X}$ chromosome inactivation. Biochim Biophys Acta 2016, 1859:112-120

13. Perlot T, Li G, Alt FW: Antisense transcripts from immunoglobulin heavy-chain locus V(D)J and switch regions. Proc Natl Acad Sci U S A 2008, 105:3843-3848

14. Bolland DJ, Wood AL, Johnston CM, Bunting SF, Morgan G, Chakalova L, Fraser PJ, Corcoran AE: Antisense intergenic transcription in V(D)J recombination. Nat Immunol 2004, 5:630-637

15. Sun K, Lai EC: Adult-specific functions of animal microRNAs. Nat Rev Genet 2013, 14:535-548

16. Pelechano V, Steinmetz LM: Gene regulation by antisense transcription. Nat Rev Genet 2013, 14:880-893

17. Leonardo TR, Schultheisz HL, Loring JF, Laurent LC: The functions of microRNAs in pluripotency and reprogramming. Nat Cell Biol 2012, 14:1114-1121

18. Kreidberg JA, Sariola H, Loring JM, Maeda M, Pelletier J, Housman D, Jaenisch R: WT-1 is required for early kidney development. Cell 1993, 74:679-691

19. Martinez-Estrada OM, Lettice LA, Essafi A, Guadix JA, Slight J, Velecela V, Hall E, Reichmann J, Devenney PS, Hohenstein P, Hosen N, Hill RE, Munoz-Chapuli R, Hastie ND: Wt1 is required for cardiovascular progenitor cell formation through transcriptional control of Snail and E-cadherin. Nat Genet 2010, 42:89-93

20. Alberta JA, Springett GM, Rayburn H, Natoli TA, Loring J, Kreidberg JA, Housman D: Role of the WT1 tumor suppressor in murine hematopoiesis. Blood 2003, 101:2570-2574
21. Vujanic GM, Kelsey A, Perlman EJ, Sandstedt B, Beckwith JB: Anaplastic sarcoma of the kidney: a clinicopathologic study of 20 cases of a new entity with polyphenotypic features. Am J Surg Pathol 2007, 31:1459-1468

22. Casalegno-Garduno R, Schmitt A, Wang X, Xu X, Schmitt M: Wilms' tumor 1 as a novel target for immunotherapy of leukemia. Transplant Proc 2010, 42:3309-3311

23. Ritchie MF, Zhou Y, Soboloff J: WT1/EGR1-mediated control of STIM1 expression and function in cancer cells. Front Biosci 2011, 16 : 2402-2415

24. Ellisen LW, Carlesso N, Cheng T, Scadden DT, Haber DA: The Wilms tumor suppressor WT1 directs stage-specific quiescence and differentiation of human hematopoietic progenitor cells. EMBO J 2001, 20: 1897-1909

25. Teitelbaum SL: Bone resorption by osteoclasts. Science 2000, 289: 1504-1508

26. Watanabe T, Kukita T, Kukita A, Wada N, Toh K, Nagata K, Nomiyama H, Iijima T: Direct stimulation of osteoclastogenesis by MIP-1alpha: evidence obtained from studies using RAW264 cell clone highly responsive to RANKL. J Endocrinol 2004, 180: 193-201

27. Kukita T, Wada N, Kukita A, Kakimoto T, Sandra F, Toh K, Nagata K, Iijima T, Horiuchi M, Matsusaki H, Hieshima K, Yoshie O, Nomiyama H: RANKL-induced DC-STAMP is essential for osteoclastogenesis. J Exp Med 2004, 200:941-946

28. Kukita A, Kukita T, Hata K, Kurisu K, Kohashi O: Heat-treated osteoblastic cell (ROS17/2.8)-conditioned medium induces the formation of osteoclast-like cells. Bone Miner 1993, 23:113-127

29. Kukita A, Kukita T, Shin JH, Kohashi O: Induction of mononuclear precursor cells with osteoclastic phenotypes in a rat bone marrow culture system depleted of stromal cells. Biochem Biophys Res Commun 1993, 196:1383-1389

30. Kukita A, Kukita T, Ouchida M, Maeda H, Yatsuki H, Kohashi O: Osteoclast-derived zinc finger (OCZF) protein with POZ domain, a possible transcriptional repressor, is involved in osteoclastogenesis. Blood 1999, 94:1987-1997

31. Toh K, Kukita T, Wu Z, Kukita A, Sandra F, Tang QY, Nomiyama H, Iijima T: Possible involvement of MIP-1alpha in the recruitment of osteoclast progenitors to the distal tibia in rats with adjuvant-induced arthritis. Lab Invest 2004, 84:1092-1102

32. Xu LX, Kukita T, Yu H, Nakano Y, Koga T: Expression of the mRNA for types I and II interleukin-1 receptors in dental tissues of mice during tooth development. Calcif Tissue Int 1998, 63: $351-356$

33. Moorwood K, Charles AK, Salpekar A, Wallace JI, Brown KW, Malik K: Antisense WT1 transcription parallels sense mRNA and protein expression in fetal kidney and can elevate protein levels in vitro. J Pathol 1998, 185:352-359

34. Dallosso AR, Hancock AL, Malik S, Salpekar A, King-Underwood L, Pritchard-Jones K, Peters J, Moorwood K, Ward A, Malik KT, Brown KW: Alternately spliced WT1 antisense transcripts interact with WT1 sense RNA and show epigenetic and splicing defects in cancer. RNA 2007, 13:2287-2299

35. Grigoriadis AE, Wang ZQ, Cecchini MG, Hofstetter W, Felix R, Fleisch HA, Wagner EF: c-Fos: a key regulator of osteoclastmacrophage lineage determination and bone remodeling. Science 1994, 266:443-448

36. Takayanagi H, Kim S, Koga T, Nishina H, Isshiki M, Yoshida H, Saiura A, Isobe M, Yokochi T, Inoue JI, Wagner EF, Mak TW, Kodama $\mathrm{T}$, Tanigucghi $\mathrm{T}$ : Induction and activation of the transcription factor NFATc1 (NFAT2) integrate RANKL signaling in terminal differentiation of osteoclasts. Dev Cell 2002, 3:889-901

37. Kukita A, Kukita T, Nagata K, Teramachi J, Li YJ, Yoshida H, Miyamoto H, Gay S, Pessler F, Shobuike T: The transcription factor FRI-1/OCZF/LRF is expressed in osteoclasts and regulates RANKLinduced osteoclast formation in vitro and in vivo. Arthritis Rheum 2011, 63:2744-2754 
38. Tsuji-Takechi K, Negishi-Koga T, Sumiya E, Kukita A, Kato S, Maeda T, Pandolfi PP, Moriyama K, Takayanagi H: Stage-specific functions of leukemia/lymphoma- related factor (LRF) in the transcriptional control of osteoclast development. Proc Natl Acad Sci U S A 2012, 109:2561-2566

39. Sugatani T, Hruska KA: Down-regulation of miR-21 biogenesis by estrogen action contributes to osteoclastic apoptosis. J Cell Biochem 2013, 114:1217-1222

40. Franceschetti T, Kessler CB, Lee SK, Delany AM: miR-29 promotes murine osteoclastogenesis by regulating osteoclast commitment and migration. J Biol Chem 2013, 288:33347-33360

41. Mizoguchi F, Murakami Y, Saito T, Miyasaka N, Kohsaka H: miR-31 controls osteoclast formation and bone resorption by targeting RhoA. Arthritis Res Ther 2013, 15:R102

42. Lee Y, Kim HJ, Park CK, Kim YG, Lee HJ, Kim JY, Kim HH: MicroRNA-124 regulates osteoclast differentiation. Bone 2013, 56: 383-389

43. Guo LJ, Liao L, Yang L, Li Y, Jiang TJ: MiR-125a TNF receptorassociated factor 6 to inhibit osteoclastogenesis. Exp Cell Res 2014, $321: 142-152$
44. Cheng P, Chen C, He HB, Hu R, Zhou HD, Xie H, Zhu W, Dai RC, Wu XP, Liao EY, Luo XH: miR-148a regulates osteoclastogenesis by targeting V-maf musculoaponeurotic fibrosarcoma oncogene homolog B. J Bone Miner Res 2013, 28:1180-1190

45. Zhang J, Zhao H, Chen J, Xia B, Jin Y, Wei W, Shen J, Huang Y: Interferon-beta-induced miR-155 inhibits osteoclast differentiation by targeting SOCS1 and MITF. FEBS Lett 2012, 586:3255-3262

46. Shibuya H, Nakasa T, Adachi N, Nagata Y, Ishikawa M, Deie M, Suzuki O, Ochi M: Overexpression of microRNA-223 in rheumatoid arthritis synovium controls osteoclast differentiation. Mod Rheumatol 2013, 23:674-685

47. Krzeszinski JY, Wei W, Huynh HD, Jin Z, Wang X, Chang TC, Xie XJ, He L, Mangala LS, Lopez-Berestein G, Sood AK, Mendell JT, Wan Y: miR-34a blocks osteoporosis and bone metastasis by inhibiting osteoclastogenesis and Tgif2. Nature 2014, 512:431-435

48. Sleutels F, Zwart R, Barlow DP: The non-coding Air RNA is required for silencing autosomal imprinted genes. Nature 2002, 415:810-813

49. Renfree MB, Ager EI, Shaw G, Pask AJ: Genomic imprinting in marsupial placentation. Reproduction 2008, 136:523-531 